\title{
How do doctoral students in STEM fields engage in scientific knowledge practices?
}

\author{
Jenna Vekkaila ${ }^{a}$, Viivi Virtanen ${ }^{a}$, Jani Kukkola ${ }^{b}$, Liezel Frick ${ }^{c}$, Kirsi Pyhältö ${ }^{a}$ \\ ${ }^{a}$ Centre for University Teaching and Learning (HYPE), University of Helsinki, Helsinki, Finland; \\ ${ }^{b}$ Department of Philosophy, History and Arts, University of Helsinki, Finland; \\ 'Department of Curriculum Studies, Stellenbosch University, Stellenbosch, South Africa.
}

Article received 1 August 2018 / Article revised 25 November / Accepted 31 January / Available online 22 February 2019

\begin{abstract}
Knowledge creation is at the core of scientific endeavour. As early career researchers, doctoral students take part in knowledge creation through engaging in various knowledge practices and make their original contribution to knowledge, and become experts in their particular domain. However, our understanding of what doctoral knowledge practices entails is still insufficient. For this study, a total of 34 doctoral students from STEM fields, including natural sciences, bio- and environmental sciences and medicine were interviewed to gain a better understanding of the kinds of knowledge practices in which doctoral students in the sciences engage. The data were collected with semi-structured interviews, which were qualitatively content analysed. The results showed that the participants mostly described activities that were established everyday knowledge practices of the researcher community (75\%), whereas practices that were innovative (25\%), entailing transformation of the current practices and developing new ones, were less often reported. Moreover, the practices were typically collective, involving the students, their supervisors or other members of their research groups (67 $\%)$. Further investigation showed that the participants were typically actively engaged in knowledge practices (79\%) rather than just adapting existing ones (13\%). Perceiving oneself as a bystander was even less typical (8\%). The significance of this study lies in exploring doctoral students' self-reported knowledge practices in STEM fields, and demonstrates that they perceive themselves as actively and collaboratively engaged in creating knowledge.
\end{abstract}

Keywords: Doctoral training; Doctoral student; Qualitative study; Knowledge practice; STEM fields 


\section{Introduction}

Knowledge creation is at the core of scientific endeavour. Doctoral students are key players in knowledge creation within any university or discipline since they contribute to the endeavour by producing an original contribution in the form of doctoral dissertation, and by extending the knowledge boundaries of a particular discipline (see e.g., the United Kingdom Quality Assurance Agency for Higher Education, 2008). Therefore, they should also be a key interest to both universities and disciplinary communities that stand to benefit from such advances in knowledge. Knowledge creation takes place through knowledge practices, entailing various disciplinary research activities such as data collection, analysis, article writing, elaboration of concepts and theories, planning a research project, and presenting research. In STEM fields (the abbreviation STEM $^{1}$ referring to science, engineering, technology and mathematics will be used in this article) such practices are suggested to be typically collective (Hakkarainen et al., 2014): doctoral research in STEM fields is typically focused on solving shared research problems related to a supervisor's research projects, pursuing article-based dissertations that consist of co-authored internationally refereed journal articles, and working intensively in relatively strong researcher communities, including several doctoral students, postdocs, and academic staff. Yet, not all the researcher communities in the STEM fields embrace collective knowledge practices, nor do all doctoral students have similar access to such practices even if they may exist in their communities. Accordingly, in order to create an optimal learning environment for knowledge creation for doctoral students in STEM fields, a better understanding of the knowledge practices, and ways in which the students engage in these practices during their studies, is needed. The study aims to contribute to bridging the gap in the literature in the field by exploring the kinds of knowledge practices in which doctoral students in STEM fields engage during their studies. The knowledge practices are explored in the framework of socioconstructivist views of learning (see e.g. Sfard, 1998; Paavola, Lipponen, \& Hakkarainen, 2004) by drawing on the seminal work on" knowledge building" by Nonaka and Taceukhi (1995), Engeström (1999), and Bereiter (2002).

\subsection{Knowledge practices as key for knowledge creation}

Knowledge creation is a socially embedded endeavour (John-Steiner, 2000), rooted in the researcher community typically comprising of supervisors, other senior scholars, post-doctoral researchers, doctoral students, and both national and international researcher networks (McAlpine \& Norton, 2006; Pyhältö \& Keskinen, 2012) sharing the same object of activity and knowledge artefacts such as research interest, frameworks, and/or methods. This has several consequences. The knowledge creation takes place in the researcher communities via knowledge practices, which are the socially created ways in which scientists think, interact, and engage in their day-to-day work (Brew et al., 2011; McAlpine \& Åkerlind, 2010) while carrying out research enquiries. Such practices entail, for instance, various methods employed in research, frameworks utilised, research designs carried out, and scientific writing genres applied. As a result, doctoral student learning is highly embedded in the knowledge practices, not only in terms of knowledge acquisition (a mental process of individual learning) and knowledge participation (a process of being socialised into an epistemic community), but also in terms of the deliberate process of creating new knowledge that has the potential to transform the student's ways thinking and behaving (Hakkarainen et al., 2004, 2013).

Prior empirical research on doctoral research knowledge practices is very limited. Few prior studies indicate that doctoral students do engage to different extents in different kinds of knowledge practices, and that differences between the researcher communities in this regard occur. Hakkarainen and his colleagues (2013), for instance, showed that doctoral students in cutting edge research groups in medicine and in natural sciences were most typically engaged in collective inquiry efforts. In a more recent study (2014) on leaders of national centers of excellence in the sciences, it was shown that professors aimed at cultivating the pursuit of collectively shared research objects, the pursuit of externally reviewed co-authored journal articles, and were

\footnotetext{
${ }^{1}$ We included Medicine in STEM, since in Finland physics, chemistry, and biology are the contents of entrance examination into studying medicine, and in the research intensive university the master students from biology often do their doctorates in medicine.
} 
focused on collective supervision (Hakkarainen et al., 2014). The findings imply that in the best, cutting-edge research communities, the aim of such communities is often to deliberately involve doctoral students in their collective knowledge practices - including the co-construction of goals, reciprocal monitoring and planning of research, and the shared regulation of joint cognitive processes in complex problem-solving (e.g., Hadwin \& Oshige, 2011; Volet, Vauras, \& Salonen, 2009), co-authoring, hard work and intensive training - to become members of the research communities (Florence \& Yore, 2004; Kamler 2008; Hakkarainen et al. 2013). Through sustained engagement, new doctoral students are gradually socialized into the knowledge practices that at its best allow them to work at the frontiers of knowledge and transform their ways of thinking and behaving (Holmes, 2004). A great deal of this kind of learning takes place through horizontal (between-peer) (see Fenge, 2012) and vertical (between newcomers and senior researchers) knowledge sharing. Engaging in the cutting-edge knowledge practices allows doctoral students' co-evolvement and co-development along with their research problems and co-authored articles, and eventually 'authoring themselves' as full-members of top researcher communities (Holland et al., 1998).

However, knowledge practices should not be seen as a singular construct. Accordingly, at least distinction between the established knowledge practices (commonly known in the community that everyone needs to master) and innovative practices (that are typically novel or recently transformed), can be made (Hakkarainen et al., 2004). Moreover, the practices may vary from individual to collective, and from routine practices related to supporting knowledge building to more fluid and innovative practices, which foster the solving of emergent and novel problems (e.g., Hakkarainen et al., 2013) that mediate progress towards new scientific discoveries. The practices can also be more or less explicit and intentional. Established knowledge practices are more often tacit, since they are well mastered by the established members of the researcher community than in the case of newly developed innovative practices that often still require extra effort to maintain. In addition, the practices are not static in nature; instead, they constantly and intentionally evolve and change in the interplay between individuals and their communities (Lave \& Wenger, 1991). Learning about these practices and how to participate in them is essential for becoming a scientist (e.g., Becher \& Trowler, 2001).

The knowledge practices are to a certain extent context dependent. In STEM fields, solving complex problems through laboratory or fieldwork often requires intensive group-based collaborative knowledge practices (Cumming, 2009; Delamont \& Atkinson, 2001) and expertise is distributed among the various researchers at different career phases. This is especially typical in large-scale research projects with many staff members and where a variety of research instruments are utilised (e.g., Furner, 2003). Moreover, researcher groups often develop their own set of distinctive knowledge practices that evolve over the time. The knowledge practices of the researcher community determine to a great extent not only the quality of their research outputs, but also what the doctoral students learn during their studies, and the overall quality of the doctoral experience. In addition, individual variation between the students in how they engage in these practices is likely to occur. Accordingly, in order to understand the influence such practices may have on the students, we need to explore what kinds of knowledge practices doctoral students engage in, and how they engage in them.

\subsection{Doctoral student engagement in knowledge practices}

Doctoral students themselves can engage differently within the knowledge practices provided by the researcher communities (Hopwood, 2010; Mathieson, 2011). They can, for instance, adopt, adapt, or withdraw from the practices, and their involvement or lack thereof may eventually modify the practices i.e. display agentic behaviours (Hopwood, 2010; Pyhältö \& Keskinen, 2012). This includes working with others to expand the "object of activity", by recognizing the motives and resources of others, interpreting them, and aligning one's own responses to these interpretations with the responses of others involved while expanding knowledge in terms of the doctoral project (Pyhältö \& Keskinen, 2012). Because sense of agency, while internal, is always constructed in a physical, social, and cultural context, the researcher community can either promote or hinder doctoral students' sense of agency (O' Meara, Terosky, \& Neumann, 2008). Variation across the doctoral students in their experienced ability to exercise their agency is based on a variety of personal, social, and organizational resources and demands at hand (O' Meara \& Campbell, 2011). Therefore, an important aspect of developing relational agency is having an opportunity to participate and contribute (Greeno, 2006; Lipponen \& Kumpulainen, 2011; Pyhältö, Pietarinen \& Soini, 2012) to the knowledge practices of the researcher community (Hancock, Hughes, \& Walsh, 2017). This requires creating the kinds of practices in which doctoral 
students are seen and treated as accountable researchers. However, the students' active and responsive collaboration with the researcher community that makes it possible to expand understanding and create new knowledge cannot be taken for granted (Pyhältö \& Keskinen, 2012). Hence students can display various degrees of agency in the knowledge practices provided by the researcher community ranging from active and interactional agent, to obedient employer, whose task is to learn "the rules of the game" and carry tasks given by the senior members of the researcher community. The ability of doctoral students to participate in knowledge creation is shown to be determined both by individual attributes, such as their motivation, skills, and ability to carry out agentic behaviour (Jazvac-Martek, Chen, \& McAlpine, 2011; McAlpine \& Amundsen, 2009; see also Bandura, 2001; Hadwin \& Oshige, 2011), as well as researcher community attributes, such as the way in which doctoral students are introduced to the community, the quality and quantity of supervisory and researcher community support provided, and the nature of practices in the given community (e.g., Delamont \& Atkinson, 2001; Gardner, 2007; Golde, 2010; Jazvac-Martek et al., 2011).

At its best, from the beginning of their doctoral processes students are involved in the knowledge practices, which are focused on the knowledge objects that enhance both knowledge and associated practices (Hakkarainen, et al., 2004; Walker et al., 2008). It has been suggested that in order for doctoral students to create new ideas, they first need a foundation for their creative actions - that is, they must master the existing frameworks, their rules and limits (Frick \& Brodin, 2014). Thus, engaging in shared and innovative knowledge practices enables doctoral students to surpass their individual limitations and create new ideas (e.g., Walker et al., 2008). This further results in changes both in the relationship between the researchers and their working environment, and in shared knowledge objects (e.g., Hakkarainen et al., 2004; Lave \& Wenger, 1991). Yet, Pyhältö \& Keskinen (2012) found that doctoral students in behavioural sciences, humanities and medicine rarely displayed agentic behaviours within their researcher communities. Prior studies imply that the knowledge practices of scientific communities play a central role in the process of learning to become a scientist, yet our understanding of the nature and function of knowledge practices, especially among STEM field doctoral students, is insufficient.

\section{Aim of the study}

Since no research (empirical or non-empirical) exists on doctoral students' knowledge practices in STEM areas, the aim of this study was to gain a better understanding of the kinds of knowledge practices in which doctoral students in STEM fields engage during their doctoral process. In order to reach the aim, the study addressed two complementary research questions; firstly, the kinds of knowledge practices reported by the doctoral students were identified, and secondly, the ways in which students participated into these practices were explored.

\section{Methods}

\subsection{Finnish doctoral education in STEM fields}

Finnish doctoral education in the sciences (Pyhältö, Stubb, \& Tuomainen, 2011) is based on the European model. Conducting doctoral thesis research is embedded in the activities of the research community. The doctorate involves a dissertation and its public defence. It is complemented with coursework (total 60-80 ECTS) that is based on personal study plans, typically including international conferences and some methodological studies. Doctoral education in Finland is outlined in more detail by Pyhältö, Nummenmaa, Soini, Stubb, and Lonka (2012).

Our study includes science, medicine, and bio- and environmental sciences. Considering academic research they all can be viewed as natural sciences in which research is based on empirical evidence from observation and experimentation with mathematics as crucial partner. In Finland physics, chemistry, and biology are the contents of entrance examination into studying medicine, and in the research-intensive university the master students from biology often do their doctorates in medicine. Hence, we use in this paper 
the abbreviation STEM with medicine included. In Finnish science, medicine, and bio- and environmental sciences, the most common type of doctoral thesis is a summary of articles. Each doctoral student is required to publish from three to five articles in peer-reviewed international journals. The articles are often co-authored with the supervisors. Doctoral students in these fields usually work on their PhDs full time, and the typical completion time varies from four to six years. The key distributives of doctoral education in the faculties of bio- and environmental sciences, medicine and science are reported in Table 1 . There are some differences between the faculties. Most doctoral students conduct their work alone in science whereas in medicine and bio- and environmental sciences the work is usually conducted in the research group. Further, the science students are less often engaged in the doctoral programs compared to their colleagues in the other two faculties. Yet the graduation time is shorter in science and medicine than in bio- and environmental sciences. The original survey data for the analysis was collected in 2011 with a broad range of disciplines included (Pyhältö, Stubb, \& Tuomainen, 2011), and in light of that, the three faculties share a quite similar system of doctoral education. However, particularly the differences in research group status may have effect on the knowledge practices identified from the doctoral students' interviews.

Table 1

The structure of doctoral education in the faculties under study: Doctoral students' (N) membership of doctoral program and research group, typical form of conducting thesis, and typical graduation time (see original data; Pyhältö, Stubb, \& Tuomainen, 2011).

\begin{tabular}{|c|c|c|c|c|c|c|c|c|c|}
\hline Faculty & $\mathrm{N}$ & Docts & ggram & Resea & group & & Form of $\mathrm{t}$ & esis & Graduation \\
\hline & & no & yes & alone & group & both & $\begin{array}{l}\text { monogra } \\
\text { ph }\end{array}$ & article & typical \\
\hline $\begin{array}{l}1 \text { Bio- and } \\
\text { environmental } \\
\text { sciences }\end{array}$ & 111 & $53 \%$ & $47 \%$ & $18 \%$ & $56 \%$ & $1 \%$ & $1 \%$ & $93 \%$ & 6 years \\
\hline 2 Medicine & 141 & $55 \%$ & $45 \%$ & $18 \%$ & $50 \%$ & $1 \%$ & $1 \%$ & $96 \%$ & 4 years \\
\hline 3 Science & 157 & $62 \%$ & $38 \%$ & $40 \%$ & $23 \%$ & $7 \%$ & $7 \%$ & $81 \%$ & 4 years \\
\hline
\end{tabular}

\subsection{Participants}

A total of 34 doctoral students from STEM fields (7 participants from the natural sciences, 7 participants from medicine, and 20 participants from the bio- and environmental sciences) participated in the study. They were all conducting their research and theses at a large research-intensive Finnish university. All the participants had a master's degree; most of the participants $(n=29)$ were full-time doctoral students and five were part-time. All the participants were pursuing a summary of articles, but they were in different phases of their doctoral process: five were in the beginning of the doctoral process, meaning that they were typically launching their research projects, collecting or analysing data, or writing their first or second article. Nine of the participants were in the middle part of the process, which typically included data analysis and writing a third or fourth article. Most of the participants $(n=16)$ were in the last part of the process, which typically meant finalizing the last articles and the summary of the articles. Four participants had already defended their doctoral theses. All the participants were interviewed on a voluntary basis.

\subsection{Data collection}

Data were collected by employing semi-structured interviews (e.g., Kvale, 2007). The interview protocol was designed to investigate the doctoral students' experiences of their thesis processes and their views of themselves within these processes (Stubb, Pyhältö, \& Lonka, 2014). All interviews were conducted by members of the authors' research group. The interviews lasted from 22 minutes to almost three hours. The interviews were recorded and transcribed verbatim. 


\subsection{Analysis}

The interview data were qualitatively content analysed (e.g., Creswell, 2012) by relying on an abductive strategy (e.g., Morgan, 2007). Hence, when categorising the data, observations and prior understanding based on theories were repeatedly assessed in relation to each other by combining data-grounded (Harry, Sturges, \& Klingner, 2005; Mills, Bonner, \& Francis, 2006) and theory-guided analysis strategies (Creswell, 2012) in order to acquire the most accurate possible understanding of doctoral students' experiences of knowledge practices. The analysis included four complementary phases.

At first, all text segments related to knowledge practices were identified. These included all doctoral students' expressions of conducting research work alone or together with other researchers. The criteria for the text segments, which where coded as experiences of knowledge practices, were that they involved a description of research activities and the object of activity (e.g., data collection, analysis, article writing, elaboration of concepts and theories, planning a research project, presenting research). The analysis resulted in 192 text segments from 34 interviews that were included in the further analysis. The units ranged from a couple of sentences to a dozen sentences.

Secondly, the knowledge practices identified in the first phase were coded according to the quality of the practices into two exclusive categories by applying a model proposed by Hakkarainen et al. (2004): 1): Established practices: including text segments in which the practices are reported to be commonly known in the community, or practices that everyone needs to adapt; and 2) Innovative practices: including text segments in which the practices are reported to be modified from the existing or new practices.

Thirdly, the knowledge practices were further categorised into two categories based on whether they were described as individual or collective. The analysis yielded two categories: 1) Individual knowledge practices, consisting of descriptions of working alone with the research; and 2) Collective knowledge practices, consisting of reports of community-based activities in which two or more researchers are involved.

At the fourth analytical phase, all the knowledge practices were coded further into three categories according to how the doctoral students described their roles in the practices: 1) Active, containing expressions of being an intentional participant who can affect the activities; 2) Adaptation, containing descriptions of being a passive participant in the practice or doing activities that someone else has ordered them to do; and 3) Bystander, containing reports of not being involved in or having an unorganized perception of one's role in the practice.

The analysis process was conducted by the first, the second and the third authors. The categories derived from the analysis were critically assessed by the research group at the end of each analysis phase in order to enhance the trustworthiness and credibility of the analysis and results (e.g., Miles \& Huberman, 1994). In the few cases of disagreement, a consensus of final categorization was reached through discussion amongst the researchers. To increase the reliability of our analysis parallel coding was carried out with $67 \%$ of the data (total of 129 text segments) independently by two co-authors. The inter-rater reliability for each of the analysis phase were: The agreement range was $100 \%$ (first phase); $81 \%$ (second phase), $95 \%$ (third phase) to $74 \%$ (fourth phase). The few cases of disagreement (particularly phase 2 and 4 ) we relied on coding of the co-author who had background in the STEM-field research, since we presumed that she was more familiar with the knowledge practices of the STEM fields. In the Findings section, we provide direct quotations from the participants' descriptions, translated from Finnish to English. The quotations were selected to illustrate the particular category as well as to highlight the differences between the categories. For each category, there were several potential illustrative quotations from each discipline available. The most comprehensive quotations were chosen from each category while keeping at the same time track that all disciplines were equally represented.

\section{Results}

The doctoral students described a variety of knowledge practices $(\mathrm{f}=192)$. The practices ranged from individual work with research instruments to dialogues about theories and observation, as well as shared problem solving and making new discoveries. The reported practices also differed in terms of how established 
or innovative they were, as described by the participants. Furthermore, the participants described their role in the reported practices in varying ways.

\subsection{Established and innovative knowledge practices}

The majority of all the knowledge practices reported were established everyday practices cultivated by the researcher community $(75 \%)$. Such practices typically involved mastering and using research instruments and methods, defining and planning the research topics and processes. The students also described practices related to scientific writing and publishing. One of the participants described such a practice in the following way:

In the beginning, my time was spent grasping the laboratory practices and that sort of stuff. And I do use all of them quite diversely, the different laboratory techniques, I mean. And they are demanding - I didn't even learn them at first. So, they do require a slow and steady pace to get the hang of them. (Medicine 2)

Occasionally, the students described established practices resulting in a discovery. The established practices resulting the discoveries were often cultivated and sustained by the researcher communities for long time. In these cases, the method itself was established and well-known, but it was used in a way that resulted in originality, as the following excerpt shows:

In a way, the techniques I use in that [study] are the ones that have been the practice in many laboratories for a long time, but in many places these are no longer used. Still, our group has trusted that this is the way to go... in the end we took a real risk and it turned out to be fruitful, and of course that was really motivating. (Bio 2)

Sometimes the participants reported practices that were innovative, entailing transformation of the current practices and developing new ones. These practices were less typical (25\%) compared to established practices. Innovative practices are the ones of utmost interest with knowledge creation at issue. Innovative practices typically emerged in situations where established ones did not work or did not provide solutions for the problems faced. Accordingly, they were characterised by learning from errors. The innovative practices were either reformed or modified from established ones, or new practices that were just created for solving novel problems. These practices were typically related to developing research ideas and theoretical observations, solving empirical problems and mastering research techniques, as well as getting results and making discoveries. The new ways of doing were often associated with aiming at, or actually constructing, new knowledge: a new research idea, theoretical observation, or scientific discovery. Occasionally, the students faced research related problems and found solutions on their own:

So I have been testing different techniques as a kind of pioneer work, as there hasn't been anyone in the research group who's used these methods... I have, kind of, made these tools up for myself and that is the reason why it has taken such a long time... and I often find myself at a dead end. (Bio 18)

\subsection{Collective and individual knowledge practices}

The participants described that the knowledge practices involved not only the students themselves, but also others, typically their supervisors, peers or other researchers from their researcher groups. Hence, the reported practices were mostly collective $(67 \%)$. Resulting from the fact that research was often carried out in research groups (Table 1). The students reported that engaging in conceptual discussion and working with theoretical ideas, defining and planning their research work, as well as mastering research techniques and writing a publication were the kinds of practices that involved their supervisors, other senior researchers and peers. For instance, the supervisors and colleagues were often active in providing suggestions and guidelines for their students in choosing their research topics, as well as planning their research processes:

Depending on the article I've been working on, many of my colleagues have collaborated with me...discussing how to do this and this. Depending on the research questions, the procedure has been different with different people. So maybe this says something about the multidisciplinarity we've had, having all these different people with their different viewpoints involved in a single project. (Natural science 4) 
Further, while typically the collective practices were also described as established activities, interestingly, there were more descriptions of innovative activities among collective practices than among individual practices. In STEM fields, solving complex problems through laboratory or field research often requires intensive group-based collaborative research practices resulting that not only knowledge creation but also researcher development is highly embedded in intensive group-based collaborative research practices. One participant expressed how he had started to develop his own research ideas and increasingly became involved in dialogues throughout the doctoral process:

In the beginning, it was mostly the supervisors who had the ideas-that we could do things this or that way. But the longer it took, the more I got into the practicalities and learned to deal with them. After that, I've been able to think more about what I want to research next, and to bring more and more of my own ideas to the brainstorming. (Medicine 3)

Participants described a third of all the reported practices as individual (33\%), such as working on their own and how they learned to use research methods, instruments and devices through individual study or experimentation. The students also described their individual responsibilities and the challenges they faced, such as experiences of being without support, as one participant describes:

So if the group does something for the first time. I feel that it's sort of my responsibility. And it slightly burdens me, because I haven't got any training for that. And the supervisors, they are clearly not able to help. Then you feel quite alone. (Medicine 2)

\subsection{The engagement of doctoral students in knowledge practices}

Further investigation showed that the students typically experienced being actively engaged in knowledge practices $(79 \%)$. Hence, they perceived themselves as active actors and intentional participants who were able to affect activities and make decisions in the practice at hand. This is a key for cultivating relational agency both in terms of the engaging in knowledge creation in order to deliver original research output as well as in terms of becoming full member of the researcher community. Active engagement was described in established and innovative, collective and individual practices related to using and mastering research methods, instruments, or techniques, as well as working with conceptual and theoretical problems, and developing and sharing ideas:

I just went through and compared the comments, and there was this sort of eureka moment I had, that maybe all I need to do is to decide for myself. I realized that I have my own opinion about where this should go, and it was very close to what one of my supervisors thought as well. But, it was also against the view of my other supervisor. But then again, in the end, I just made my own decision. And I came to the conclusion that even in the so-called 'hard sciences' there really isn't always exactly one truth to follow. (Natural science 3)

In the following, another participant expresses how he had an active role and control over his research work:

I've been given a lot of room for my own self-guidance, and my own thoughts and implementations. And I've never really had any difficulties in getting my own thoughts about what I wanted to do heard. So in that regard it's been quite rewarding, and I've been given the opportunity to do plenty of different kinds of things. (Bio 18)

Doctoral students less frequently described adapting existing activities and ideas. Such experiences were only occasionally reported among all the instances of knowledge practices $(13 \%)$. A characteristic of these experiences was that the students considered themselves to be passive participants who were doing activities and work that someone else wanted or had ordered them to do. Accordingly, developing relational agency is not easy or self-evidently resulted from carrying out doctoral research. If doctoral students are not given opportunity to participate and contribute actively to the knowledge practices of their researcher community, including opportunity for experimenting and even to fail, also the opportunities for learning to become a researcher are limited. In some cases, the students believed that the way others carried out the activities was not meaningful for them. Such roles were often described in association with established and collective practices. Furthermore, these descriptions were typically related to planning the research topic and 
process, developing research ideas, as well as writing an article. One of the participants expressed his adaptive role in choosing and conducting his doctoral research in the following way:

I was told that I should be working on this doctoral dissertation topic. They needed a candidate for it. And I just went and started in that project where they had the opening for one more student and was stuck there. I could not choose the topic myself, but partly there was kind of pressure to have this topic that was worth four academic articles. And I need those four. But in this situation, it is not that I can just creatively come up with something to research. Something I'd find interesting to look further into by myself. But it's just not possible. If the thing you're working on doesn't sound [to the supervisors] like it's going to be good enough, then it's not worth spending your time on, and you would be told to work on other stuff. Kind of from the top down. (Medicine 4)

Doctoral students rarely considered themselves bystanders ( $8 \%$ ), in other words, observers who were left outside the practice. Yet experiencing oneself as bystander can be considered highly problematic since it limits doctoral student's learning both in terms of becoming independent researcher, and in delivering original research output. In the cases where this did occur, they described seemingly unclear and unorganised perceptions of their role in the practice. The bystander role was typically associated with established and collective practices related to, for instance, defining and discussing the research topic and plan, designing the research questions or writing a publication. One participant described his role of a bystander in the following way:

Then, our clinician actually wrote the paper because I did not have the right clinical background for that. (Bio 6).

\section{Discussion}

Our results show that established knowledge practices played an important role in cultivating doctoral students' insights into their research, developing creative thoughts and behaviours, enabling them to define a problem space and to solve them. Such practices are typically well tested and cultivated over long period of time by the researcher community, and hence provide a grounding for its knowledge creation. Engaging doctoral students in these baseline knowledge practices is key both for becoming full member of the community and teaching them about the research and disciplinary practices, as mastery of existing ideas and tools are often a precondition for creativity. The established knowledge practices served as the basis for making discoveries and, hence, the creation of new knowledge (see also Sternberg \& Lubart, 1999). Accordingly, the established knowledge practices provided a vehicle for introducing and engaging doctoral students into the researcher communities, i.e. socialising the student as a novice into the academic community (Becher \& Trowler, 2001). They also provided a starting point for researcher development. In addition, the existence and extent of the reported innovative practices evident from our dataset is encouraging, since it implies that doctoral students are contributing to novel ways of working, and the transformation of their respective fields of study (Trafford \& Leshem, 2009; Wellington, 2012). Engaging in such practices provides also opportunity to learn from the mistakes, and use them as opportunity to further cultivate the established practices. More importantly, it allows doctoral students learn how to develop new collective knowledge practices in order to create knowledge in their field.

Doctoral students are frequently found to face academic isolation and a lack of academic connections (see for example Ali \& Kohun, 2006; Austin, 2009) that hinder their progress. Our results on knowledge practices suggest that the doctoral students in the STEM fields engaged primarily in collective practices. This is partly explained by the fact that majority of the participants engaged in the intensive research group collaborations and conducted article-based dissertations including typically co-authored articles with senior members of the group. However, the result cannot be reduced into the research group status, since the majority of students in sciences reported that they did not carry out their dissertation work in the research group. Accordingly, rather than being matter of the structure, it seems to be a matter of the quality of knowledge practices developed in which doctoral students engaged in that matters. The argument follows that students can be actively engaged in collective practices even though they are not formally carrying out their dissertation 
work in the group. This finding is in accordance with our prior results on medical, humanities, and behavioural science doctoral students, which showed that more than half of the students perceived themselves as members of a scholarly community and its practices. No statistically significant differences were detected in the previous study even though in medicine the majority of the students worked in a research group and carried out articlebased dissertations, while in the humanities the students were more likely to follow a monograph dissertation format and were not formally engaged in research groups (Pyhältö, Stubb, \& Lonka, 2009). Even tough working collectively does not guarantee that doctoral students won't experience feelings of isolation, the data presented in this article can be considered encouraging since the advantages of collaboration to productivity, and thus also to knowledge creation, have been emphasised (see for example Becher \& Trowler, 2001).

The results also suggest that the doctoral students typically considered themselves active participants in knowledge practices instead of mere adapters or bystanders. This provides a good grounding for cultivating the doctoral students' relational agency within their researcher communities in terms of knowledge practices that may contribute to eventual knowledge creation. Given that research groups and collective work are typical in STEM areas, this finding is not surprising. Yet, it partly contradicts some of our earlier findings suggesting that a minority of doctoral students in humanities, behavioural sciences, and medicine perceived themselves as active relational agents in their own researcher communities (Pyhältö \& Keskinen, 2012). However, our results also imply that not all the students enjoy equal opportunities to exercise relational agency. Moreover, it is important to note that active engagement in knowledge practices in their researcher groups does not guarantee an active role in other activities of the group or in other researcher communities.

As the stakes are high for doctoral students to complete their studies in a timely manner, our findings about doctoral students' active role imply that doctoral education provided engaging learning environment for knowledge creation for the majority of our participants (see also Frick, 2010). However, taking on the role of adapter or bystander should not be viewed with outright suspicion, as mastery that supports knowledge creation requires an understanding of existing knowledge and an immersion in the field before such a field can be extended or transformed through new and original work (Dewett et al., 2005; Sternberg \& Lubart, 1999). Yet, if students spend the majority of their time as either adapters or bystanders, in which case they may become stuck in these roles, or resort to mimicking others' knowledge work rather than creating their own contribution and transforming the field in so doing it can be considered highly problematic (Kiley, 2009).

The significance of this study lies in exploring doctoral students' self-reported knowledge practices in STEM fields, and shows that they typically perceive themselves as actively and collaboratively engaged in the practices through transforming their respective fields of study. Moreover, the study indicates that doctoral knowledge creation embedded in knowledge practices in the studied STEM areas is not only an individual cognitive endeavour. Instead, it is also a collective process, which takes place in a broader scientific community, not exclusively limited in conducting doctoral dissertation in the research group

\subsection{Methodological considerations}

The strength of the chosen qualitative design was that it enabled a multifaceted and deep investigation of doctoral students' experiences of knowledge practices. In addition, the multiphase analysis enabled investigation of the knowledge practices from various perspectives. However, one problem with the used retrospective approach is that it exposes the memory effect (Cox \& Hassard, 2007), potentially resulting in difficulties for participants in recalling their experiences (Kvale, 2007). At the same time, use of the retrospective approach ensured that the participants had a chance to deeply reflect on their experiences and recall the most significant past events (Kvale, 2007). The majority of the participants were in the middle or in the last part of the doctoral process and, because of their experience, they have had more opportunities to be involved in and gain experience with various kinds of knowledge practices.

The interview data were collected from 34 doctoral students in the STEM fields from a large researchintensive university in Finland. Because of the distinctive features of the disciplines included (e.g., LindblomYlänne et al., 2006) and the limited sample size, the results should be generalised to other fields and other countries with caution. Knowledge creation practices evolve over time and, hence, further research is needed to explore the knowledge practices among researcher communities from different domains and from a longitudinal perspective. 


\subsection{Implications for doctoral education}

Our results indicate that doctoral students can have active roles and be intentional participants in various scientific knowledge practices. Further, the findings suggest that active engagement in knowledge practices can be enabled by supporting doctoral students to influence or direct the surrounding. This requires further developing strategies that promote the intentional participation of students in scientific activities and practices (Pyhältö \& Keskinen, 2012; Zhao \& Kuh, 2004). Active engagement can be supported through environments that enable doctoral students to share their knowledge and expertise with others, take more responsibility for and ownership of their research activities, and perceive themselves as contributing members of their community (e.g., Dunlap, 2006; McAlpine \& Amundsen, 2009). For instance, the more experienced members of the researcher communities, such as supervisors, senior researchers and post-doctoral fellows, could support and encourage doctoral students to take increasingly more ownership and responsibility for planning, monitoring and evaluating the everyday practices of knowledge creation. Such practices, according to our results, could be planning and conducting actual research work, theoretical problem solving, and dialogues on research ideas. Supporting the active role of doctoral students in knowledge practices is likely to be an investment in the quality of future academic work. At best, active doctoral students will become autonomous scientists who create new, high-quality knowledge.

\section{Keypoints}

- The study aims to contribute to the doctoral education literature by exploring the kinds of knowledge practices in which doctoral students in the STEM fields engage during their studies.

- The significance of this study lies in exploring doctoral students' self-reported knowledge practices.

- This study demonstrates that the doctoral students perceive themselves as actively and collaboratively engaged in the knowledge practices.

- The study concludes that active engagement in knowledge practices can be enabled by supporting doctoral students to influence or direct the surrounding knowledge creation activities.

\section{References}

Ali, A., \& Kohun, F. (2006). Dealing with isolation feelings in IS doctoral programs. International Journal of Doctoral Studies, 1(1), 21-33.

Austin, A.E. (2009). Cognitive apprenticeship theory and its implications for doctoral education: A case example from a doctoral program in higher and adult education. International Journal for Academic Development, 14(3), 173-183. https://doi.org/10.1080/13601440903106494

Bandura, A. (2001). Social cognitive Theory: An agentic perspective. Annual Review of Psychology, 52, 1-26. https://doi.org/10.1146/annurev.psych.52.1.1

Becher, T. \& Trowler, P. R. (2001). Academic tribes and territories. Intellectual enquiries and the culture of disciplines ( $2^{\text {nd }}$ ed.). Open University Press, Buckingham.

Bereiter, C. (2002). Education and mind in the knowledge age. Mahwah, NJ: Lawrence Erlbaum Associates.

Brew, A., Boud, D., \& Namgung, S. U. (2011). Influences on the formation of academics: The role of the doctorate and structured development opportunities. Studies in Continuing Education, 33(1), 51-66. https://doi.org/10.1080/0158037X.2010.515575

Cox, J. W., \& Hassard, J. (2007). Ties to the past in organization research: A comparative analysis of retrospective methods. Organization, 14(4), 475-497. https://doi.org/10.1177/1350508407078049 
Creswell, J. (2012). Qualitative Inquiry \& Research Design. Choosing Among Five Approaches (3 ${ }^{\text {rd }}$ ed.). London: SAGE Publishers.

Cumming, J. (2009). The doctoral experience in science: Challenging the current orthodoxy. British Educational Research Journal, 35(6), 877-890. https://doi.org/10.1080/01411920902834191

Delamont, S., \& Atkinson, P. (2001). Doctoring uncertainty: Mastering craft knowledge. Social Studies of Science, 31(1), 87-107. https://doi.org/10.1177/030631201031001005

Dewett, T., Shin, S. J., Toh, S. M., \& Semadeni, M. (2005). Doctoral student research as a creative endeavour. College Quarterly, 8(1), 1-20.

Dunlap, J. C. (2006). The effect of a problem-centered, enculturating experience on doctoral students' self-efficacy. Interdisciplinary Journal of Problem-based Learning, 1(2), 19-48. https://doi.org/10.7771/1541-5015.1025

Engeström, Y. (1999). Activity theory and individual and social transformation. In Y. Engeström, R. Miettinen, \& R. Punamäki (Eds.), Perspectives on Activity Theory. Learning in Doing: Social, Cognitive and Computational Perspectives (pp. 19-38). Cambridge: Cambridge University Press.

Fenge, L. A. (2012). Enhancing the doctoral journey: the role of group supervision in supporting collaborative learning and creativity. Studies in Higher Education, 37(4), 401-414. https://doi.org/10.1080/03075079.2010.520697

Florence, M. K., \& Yore, L. (2004). Learning to Write Like a Scientist: Co-authoring as an Enculturation Task. Journal of Research in Science Teaching, 41(3), 637-668. https://doi.org/10.1002/tea.20015

Frick, B. L. (2010). Creativity in doctoral education: Conceptualising the original contribution. In C. Nygaard, N. Courtney \& C.W. Holtham (Eds.), Teaching Creativity - Creativity in Teaching. Oxfordshire: Libri Publishing.

Frick, B. L. \& Brodin, E. M. (2014). Developing expert scholars: the role of reflection in creative learning. In E. Shiu (Ed.), Creativity Research: An Interdisciplinary and Multidisciplinary Research Handbook (pp. 312-333). London: Routledge.

Furner, J. (2003). Little book, big book: Before and after little science, big science: A review article, part I. Journal of Librarianship and Information Science, 35(2), 115-125. https://doi.org/10.1177/0961000603352006

Gardner, S. K. (2007). "I heard it through the grapevine": Doctoral student socialization in chemistry and history. Higher Education, 54(5), 723-740. https://doi.org/10.1007/s10734-006-9020-x

Golde, C. M. (2010). Entering different worlds. Socialization into disciplinary communities. In S. K. Gardner \& P. Mendoza (Eds.), On becoming a scholar. Socialization and development in doctoral education (pp. 79-95). Virginia, USA: Stylus Publishing, LLC.

Greeno, J. G. (2006). Authoritative, accountable positioning and connected, general knowing: Progressive themes in understanding transfer. The Journal of learning sciences, 15, 537-547. http://dx.doi.org/10.1207/s15327809jls1504_4

Hadwin, A., \& Oshige, M. (2011). Self-regulation, coregulation and socially shared regulation: Exploring perspectives of social in self-Regulated learning theory. Teachers College Record, 113(2), 240-264.

Hakkarainen, K., Hytönen, K., Makkonen, J., Seitamaa-Hakkarainen, P., \& White, H. (2013). Interagency, collective creativity, and academic knowledge practices. In A. Sannino \& V. Ellis (Eds.), Learning and collective creativity: Activity-theoretical and sociocultural studies (pp. 77-95). London: Routledge.

Hakkarainen, K., Palonen, T., Paavola, S., \& Lehtinen, E. (2004), Communities of networked expertise. Professional and educational perspectives. Amsterdam: Elsevier.

Hakkarainen, K. P., Wires, S., Keskinen, J., Paavola, S., Pohjola, P., Lonka, K., \& Pyhältö, K. (2014). On personal and collective dimensions of agency in doctoral training: medicine and natural science programs. Studies in Continuing Education, 36(1), 83-100. https://doi.org/10.1080/0158037X.2013.787982 
Hancock, S., Hughes, G., \& Walsh, E. (2017). Purist or pragmatist? UK doctoral scientists' moral positions on the knowledge economy. Studies in Higher Education, 42(7), 1244-1258. https://doi.org/10.1080/03075079.2015.1087994

Harry, B., Sturges, K. M., \& Klingner, J. K. (2005). Mapping the process: An exemplar of process and challenge in grounded theory analysis. Educational Researcher, 34(2), 3-13. https://doi.org/10.3102/0013189X034002003

Holland, D., Lachiocotte, W., Skinner, D., \& Cain, C. (1998). Identity and agency in cultural worlds. Cambridge, MA: Harvard University Press

Holmes, L. (2004). Challenging the learning turn in education and training. Journal of European Industrial Training, 28(8/9), 625-638. https://doi.org/10.1108/03090590410566552

Hopwood, N. (2010). A sociocultural view of doctoral students' relationships and agency. Studies in Continuing Education, 32(2), 103-117. https://doi.org/10.1080/0158037X.2010.487482

Jazvac-Martek, M., Chen, S., \& McAlpine, L. (2011). Tracking the doctoral student experience over time: Cultivating agency in diverse spaces. In L. McAlpine \& C. Amundsen (Eds.), Doctoral Education: Research-Based Strategies for Doctoral Students, Supervisors and Administrators (pp. 17-36). Netherlands: Springer.

John-Steiner, V. (2000). Creative collaboration. Oxford University Press.

Kamler, B. (2008). Rethinking doctoral publication practices: writing from and beyond the thesis. Studies in Higher Education, 33(3), 283-294. https://doi.org/10.1080/03075070802049236

Kiley, M. (2009). Identifying threshold concepts and proposing strategies to support doctoral candidates. Innovations in Education and Teaching International, 46(3), 293-304. https://doi.org/10.1080/14703290903069001

Kvale, S. (2007). Doing interviews. London: Sage Publications.

Lave, J., \& Wenger, E. (1991). Situated learning: Legitimate peripheral participation. Cambridge: University Press.

Lindblom-Ylänne, S., Trigwell, K., Nevgi, A., \& Ashwin, P. (2006). How approaches to teaching are affected by discipline and teaching context. Studies in Higher Education, 31(3), 285-298. https://doi.org/10.1080/03075070600680539

Lipponen, L., \& Kumpulainen, K. (2011). Acting as accountable authors: Creating interactional spaces for agency work in teacher education. Teaching and teacher education, 27, 812-819. http://dx.doi.org/10.1016/j.tate.2011.01.001

Mathieson, S. (2011). Developing academic agency through critical reflection: a sociocultural approach to academic induction programmes. International Journal for Academic Development, 16(3), 243-256. https://doi.org/10.1080/1360144X.2011.596730

McAlpine, L., \& Amundsen, C. (2009). Identity and agency: Pleasures and collegiality among the challenges of the doctoral journey. Studies in Continuing Education, 31(2), 109-125. https://doi.org/10.1080/01580370902927378

McAlpine, L., \& Norton, J. (2006). Reframing our approach to doctoral programs: An integrative framework for action and research. Higher Education Research \& Development, 25(1), 3-17. https://doi.org/10.1080/07294360500453012

McAlpine, L., \& Åkerlind, G. (2010). Academic practice in a changing international landscape. In L. McAlpine \& G. Åkerlind (Eds.), Becoming an academic. International perspectives (pp. 1-15). United Kingdom: Palgrave Macmillan.

Miles, M. B., \& Huberman, A. M. (1994). Qualitative data analysis (2nd ed.). Thousand Oaks, CA: Sage publications.

Mills, J., Bonner, A., \& Francis, K. (2006). The development of constructivist grounded theory. International Journal of Qualitative Methods, 5(1), 25-35. https://doi.org/10.1177/160940690600500103

Morgan, D. L. (2007). Paradigms lost and pragmatism regained: Methodological implications of combining qualitative and quantitative methods. Journal of Mixed Methods Research, 1(1), 4876. https://doi.org/10.1177/2345678906292462 
Nonaka I, Takeuchi H. (1995). The Knowledge Creating Company. Oxford University Press: New York.

O’ Meara, K., Terosky, A.L. \& Neumann, A. (2008). Faculty careers and work lives: A professional growth perspective. ASHE Higher Education Report, 34 (3). San Fransisco, CA: Jossey-Bass.

O’ Meara, K, \& Campbell, C. M. (2011). Faculty sense of Agency in Decisions about Work and Family. The Review of Higher Education, 34 (3), 447-476. http://dx.doi.org/10.1353/rhe.2011.0000

Paavola, S., Lipponen, L., \& Hakkarainen, K. (2004). Models of Innovative Knowledge Communities and Three Metaphors of Learning. Review of Educational Research, 74(4), 557-576. https://doi.org/10.3102/00346543074004557

Pyhältö, K., \& Keskinen, J. (2012). Doctoral students' sense of relational agency in their scholarly communities. International Journal of Higher Education, 1(2), 136-149.

Pyhältö, K., Nummenmaa, A. R, Soini, T., Stubb, J., \& Lonka, K. (2012). Research on scholarly communities and development of scholarly identity in Finnish doctoral education. In S. Ahola \& D. M. Hoffman (Eds.), Higher education research in Finland. Emerging structures and contemporary issues (pp. 337-357). Jyväskylä: Jyväskylä University Press.

Pyhältö, K., Pietarinen, J., \& Soini, T. (2012). Do comprehensive school teachers perceive themselves as active professional agents in school reforms?. Journal of Educational Change, 13(1), 95116.

Pyhältö, K., Stubb, J., \& Lonka, K. (2009). Developing scholarly communities as learning environments for doctoral students. International Journal for Academic Development, 14(3), 221-232. https://doi.org/10.1080/13601440903106551

Pyhältö, K., Stubb. J., \& Tuomainen, J. (2011). International evaluation of research and doctoral education at the University of Helsinki - To the top and out to society. Summary report on doctoral students' and principal investigators' doctoral training experiences. Retrieved from http://wiki.helsinki.fi/display/evaluation2011/Survey+on+doctoral+training

Sfard, A. (1998). On Two Metaphors for Learning and the Dangers of Choosing Just One. Educational Researcher, 27(2), 4-13. https://doi.org/10.1080/13601440903106551

Sternberg, R. J., \& Lubart, T. I. (1999). The concept of creativity: Prospects and paradigms. In R.J. Sternberg (ed.), Handbook of creativity (pp. 3-15). Cambridge: Cambridge University Press.

Stubb, J., Pyhältö, K., \& Lonka, K. (2014). Conceptions of research: the doctoral student experience in three domains. Studies in Higher Education, 39(2), 251-264. https://doi.org/10.1080/03075079.2011.651449

Trafford, V. \& Leshem, S. (2009). Doctorateness as a threshold concept. Innovations in Education and Teaching International, 46(3), 305-316. https://doi.org/10.1080/14703290903069027

United Kingdom Quality Assurance Agency for Higher Education (2008). The framework for higher education qualifications in England, Wales and Northern Ireland. Mansfield: Linney Direct.

Volet, S., Vauras, M., \& Salonen, P. (2009). Self- and social regulation in learning contexts: An integrative perspective. Educational Psychologist, 44(4), 215-226. https://doi.org/10.1080/00461520903213584

Walker, G. E., Golde, C. M., Jones, L., Conklin Bueschel, A., \& Hutchings, P. (2008). The formation of scholars. Rethinking doctoral education for the twenty-first century. San Francisco, USA: Jossey-Bass.

Wellington, J. (2012). Searching for doctorateness. Studies in Higher Education, 38(10), 1490-1503. https://doi.org/10.1080/03075079.2011.634901

Zhao, C., \& Kuh, G. D. (2004). Adding value: Learning communities and student engagement. Research in Higher Education, 45(2), 115-138. 